\title{
Effect of short-term feed restriction on production traits of brown and black plumage commercial layer strains at late phase of egg production
}

\author{
Simeon Olutoye Olawumi \\ Department of Animal Production and Health Sciences, Ekiti State University, Ado-Ekiti, Nigeria \\ Email address: \\ olawumisimeon@yahoo.com
}

To cite this article:

Simeon Olutoye Olawumi. Effect of Short-Term Feed Restriction on Production Traits of Brown and Black Plumage Commercial Layer Strains at Late Phase of Egg Production. American Journal of Agriculture and Forestry. Vol. 2, No. 2, 2014, pp. 33-38.

doi: 10.11648/j.ajaf.20140202.13

\begin{abstract}
The effect of strain and different levels of quantitative feed restriction for short time (28d) on egg production, feed consumption and efficiency, mortality and egg quality traits were evaluated during late phase of egg laying. A total number of 90 layers aged 54 weeks old, comprising 45 birds each of Isa Brown (brown plumage) and Bovan Black (black plumage) were randomly distributed into three treatment groups having three replicates each. They were placed under three feeding regimens namely, $\mathrm{T}_{1}$ (ad libitum- control), $\mathrm{T}_{2}\left(90 \%\right.$ ad libitum) and $\mathrm{T}_{3}(80 \%$ ad libitum). Data collected include egg production, mortality, feed variables, external and internal egg quality characteristics. The results revealed that strain has insignificant $(\mathrm{P}>0.05)$ effect on egg numbers during the 28 days trial regardless of treatments imposed. This means that feed restriction on short-term has no negative impact on both the brown and black feathered layer birds productivity. However, feed restriction has significant $(\mathrm{P}<0.01)$ effect on both egg numbers and hen-day egg production regardless of strain of birds. Regarding the two traits, ad libitum (control) and $90 \%$ ad libitum had similar mean values, but higher than $80 \%$ ad libitum. As per feed efficiency, brown strain has higher $(\mathrm{P}<0.01)$ mean values than the black strain. The two strains subjected to feed restriction recorded similar mean values and performed equally well in egg weight, egg length and other external and internal egg qualities. However, in albumen height and Haugh unit $(\mathrm{HU})$, brown birds had higher $(\mathrm{P}<0.01)$ mean values than black hens. Haugh unit is a measure of internal egg quality. The highest net revenue/hen and economic efficiency was recorded in $90 \%$ ad libitum $(\$ 1.19,112.26)$, intermediate $(\$ 1.06,100)$ in ad libitum and lowest $(1.10,95.28)$ in $80 \%$ ad libitum. Brown strain achieved higher $(\mathrm{P}<0.01)$ economic efficiency $(100$ vs 88.54$)$ and net revenue $(\$ 0.96$ vs $\$ 0.85)$ per hen than black strain at the end of the experimental period. There was significant strain $\mathrm{x}$ treatment interaction effect on egg number, percent egg production and feed variables. Brown feathered birds and adoption of milder feed restriction seem to hold prospect for increased production, profit and sustainability of egg producing industry.
\end{abstract}

Keywords: Strain, Feed Restriction, Haugh Unit, Egg Quality

\section{Introduction}

In livestock industry, productivity and profitability depend to a larger extent on the genetic make-up or constitution of an animal being reared for either meat or egg production. Other important factors influencing productivity include prevailing environmental conditions, management practices such as feed and feeding management and the technical knowledge of the farmers, [1]. Feed restriction in a layer flock entails limiting the number of hours birds have access to feeds or actual reduction of the amount of feeds given per day. The main goal of controlled feeding in commercial laying flock is to ensure that the birds do not build up excessive fat during production so as not to interfere with their performance. Restricted feeding according to some researchers helped in maintaining correct body weight, prevented over eating and from getting overly heavy $[2,3]$. However, there are different approaches to this concept and individual farmers are left with options best suited for his research study. Other investigators asserted that feed restriction includes: (a) limiting the bird's time to diet, (b) quantitative feed restriction, (c) use of low energy 
diet, and (d) dietary protein restriction [4].

In growing pullets and breeder chicks, quantitative feed restriction is usually employed to control growth by feeding a predetermined amount of balanced ration in order to achieve a good production during laying period [5]. The major problem associated with quantitative feed restriction programme is that of feed distribution in such a way that all the birds have equal opportunity and access to feeds [6]. Closely connected to that assertion is the fact that birds are not uniform in body weight and body weight gain, and the rate of egg production differs too. These aforementioned factors play significant effects on the amount of feeds consumed by individual bird even if they are of the same age.

In previous study, a significant effect of feed restriction on egg production in Bovan Near layer strain was documented [7]. The researchers however, reported insignificant influence of controlled feeding on egg quality traits. In contrast, other investigators reported that feed deprivation has no significant effect on egg number, hen-day egg production, egg weight and egg quality [8]. The researchers however, found significant effect of feed deprivation on yolk index and Haugh unit between Hisex Brown and Bovan White strains of layers. Feed restriction in growing pullets of egg-type and broiler breeders strains had long been advocated by previous researchers [9]. In another study, the authors observed that feed restriction during rearing period has no negative effect on egg production except when carried out during laying phase [10]. Some workers have reported that feed restriction delayed sexual maturity and reduced body weight at laying $[9,11]$.

The ever increasing cost of feed ingredients constitutes a clog in the wheel of progress in livestock industry, and this now calls for drastic cost reducing measures without compromising on the wellbeing of the birds and product quality. One of such measures is controlled feeding in laying flock, commercial and breeder pullets. It is however, important to ascertain the inherent abilities of these birds before the application of this method so as not to impede their genetic potentials in the process. Birds have different genetic constitution and production potentials, application of controlled feeding therefore, must be done with caution in order not to sacrifice product quality on the altar of saving cost and feeding management practices.

In view of arguments for and against controlled feeding in layers, this study was conceived and undertaken to evaluate and compare the response to feed restriction of brown and black feathered layer strains reared under uniform management, housing and nutritional conditions. The objective was to assess the degree of tolerance to feed restriction between the two strains and how it affects their performance in terms of egg production, egg quality traits, mortality, feed consumption, feed conversion ratio and feed efficiency. The study also aimed at evaluating cost of production and net returns from the different feed restriction levels imposed on the layer strains.

\section{Materials and Methods}

\subsection{Study Location}

The study was carried out at the Animal Breeding Unit, Teaching and Research Farm, Ekiti State University, Ado-Ekiti and lasted for four weeks during $1^{\text {st }}-29^{\text {th }}$ September, 2012. The city is situated along latitude $7^{0} 31^{1}$ and $7^{0} 49^{1}$ North of the Equator and longitude $5^{0} 71^{1}$ and $5^{0} 27^{1}$ East of the Greenwich meridian. The rainfall pattern in the agro-climatic zone had been reported [12].

\subsection{Experimental Birds}

A total number of ninety layers comprising 45 birds each of brown (Isa Brown) and black (Bovan Black) plumage layers were reared and housed in cages for the purpose of this experiment. The birds were of the same age at the time of the study and given uniform management and quality feed. During the growing period, the birds were vaccinated against Newcastle and Fowl Pox diseases, while antibiotics were administered against bacterial diseases to boost the immunity level of the birds. The birds were dewormed at three months interval and multivitamins given regularly to ameliorate the effect of vaccination and heat stress. Some other bio-security measures were taken to prevent disease transfer from external sources.

The forty-five experimental birds were on strain basis randomly divided into three treatments of 15 birds per treatment, and these were later subdivided into three replicates of five birds each. That is, we have $\mathrm{T}_{1}$ (ad libitum), $\mathrm{T}_{2}$ (90\% ad libitum) and $\mathrm{T}_{3}(80 \%$ ad libitum) representing the treatment groups and under these we have three replicates such as ad libitum $\left(\mathrm{T}_{1} \mathrm{R}_{1}, \mathrm{~T}_{1} \mathrm{R}_{2}, \mathrm{~T}_{1} \mathrm{R}_{3}\right), 90 \%$ ad libitum $\left(\mathrm{T}_{2} \mathrm{R}_{1}, \mathrm{~T}_{2} \mathrm{R}_{2}, \mathrm{~T}_{2} \mathrm{R}_{3}\right)$ and $80 \%$ ad libitum $\left(\mathrm{T}_{3} \mathrm{R}_{1}, \mathrm{~T}_{3} \mathrm{R}_{2}\right.$, $T_{3} R_{3}$ ). They were given two weeks adaptation period and fed ad libitum before the commencement of application of feed restriction. The layer diet contained $16.5 \% \mathrm{CP}$ (crude protein) and $2500 \mathrm{Kcal} / \mathrm{kg} \mathrm{ME}$ (metabolizable energy). Water was supplied ad libitum to the birds throughout the observed period.

\subsection{Data Collection}

Hen-day egg production (eggs laid in a day by living birds) and mortality were recorded on daily basis. In addition, feed consumption, feed efficiency, feed conversion ratio and economic returns were recorded for both strains of commercial layers during the experimental period (from 54-58 weeks of age)

Egg quality was measured twice: 55 and 57 weeks of age. A total number of 27 fresh eggs per strain, that is, three eggs per replicate which amounted to nine eggs per treatment were randomly selected, numbered and then weighed on treatment and breed basis on a sensitive scale. These eggs were thereafter, broken on a flat plate at equatorial region for the determination of internal egg contents. Egg quality traits evaluated included egg weight, length, width, yolk weight and height, albumen height, shell weight and shell thickness. 
Yolk and shell weight were measured using sensitive scale, while egg length, egg width, yolk height and albumen height were measured with vernier callipers.

Albumen weight was calculated by the formula:

Albumen weight $=$ egg weight $-($ yolk weight + shell weight)

Haugh unit $(\mathrm{Hu})=100 \log \left(\mathrm{H}+7.57-1.7 \mathrm{~W}^{0.37}\right)(\mathrm{Haugh}$, 1937)

$\mathrm{H}=$ albumen height in $\mathrm{mm}$

$\mathrm{W}=$ weight of egg in grammes

\subsection{Statistical Analysis}

The data from this study were subjected to a two-way analysis of variance for the effect of breed and treatment and their interactions. Means were separated by the use of Duncan New Multiple Range Test. Data were analyzed using the General Linear Model procedure of SAS software [13].

The appropriate statistical model used was:

Yijk $=\mu+\mathrm{Gi}+\mathrm{Rj}+\varepsilon \mathrm{ijk}$

Yijk = observation on kth population, of ith strain and jth feed restriction

$$
\begin{aligned}
& \mu=\text { common mean } \\
& \mathrm{Gi}=\text { fixed effect of strain }(\mathrm{i}=2) \\
& \mathrm{Rj}=\text { fixed effect of feed restriction }(\mathrm{j}=3) \\
& \varepsilon \mathrm{ijk}=\text { error term }
\end{aligned}
$$

\section{Results and Discussion}

\subsection{Cumulative Egg Number and Hen-Day Egg Production}

Averages of cumulative egg number as affected by strain and feed restriction were shown in Table 1. Strain has insignificant $(\mathrm{P}>0.05)$ effect on egg number during the 28 days trial regardless of treatments imposed. This means that feed restriction on short-term has no negative impact on both the brown (Isa Brown) and black (Bovan Nera) feathered layer birds productivity, and could be practiced to save cost and to obtain higher profit from the laying stocks. With regard to hen-day egg production, brown strain recorded higher $(\mathrm{P}<0.01)$ percentage than black strain. The difference in hen-day egg production could be attributed to their genetic variations. These results are in agreement with those of other authors $[8,13]$, who have reported that brown strains had higher hen-day production than white strains. Therefore, it can be concluded that there exist differences in egg production between brown and black strains of commercial layers when subjected to feed restriction.

Feed restriction has significant $(\mathrm{P}<0.01)$ effect on both egg number and hen-day egg production regardless of strain of birds. Pertaining to egg number, ad libitum and $90 \%$ ad libitum had similar mean values, but higher than $80 \%$ ad libitum. In the same manner, ad libitum and 90\% ad libitum recorded similar mean values in hen-day production, but superior to $80 \%$ ad libitum. This implies that milder feed restriction produces satisfactory result and can be applied to reduce cost and increase profit margin. On the other hand, severe feed restriction should be discouraged as this appears to impact negatively on birds' performance. In partial agreement to the results in this study, previous data indicated found that feed restriction has no adverse effect on hen-day egg production $[8,14]$.

\subsection{Cumulative Feed Intake, Feed Efficiency and Feed Conversion Ratio}

The results presented in Table 1 indicated that both strains consumed equal amount of feed regardless of treatments imposed during the experimental period. As per feed efficiency, brown strain has higher $(\mathrm{P}<0.01)$ mean values than the black strain. The inference is that the former utilized the feeds given efficiently than the latter, and this might be responsible for its higher hen-day production observed in this study. Similarly in line with the results in this study, [8 and 15] have shown that brown egg strain had better feed efficiency than white egg strain. However, feed conversion ratio as influenced by strain was different from what was reported for feed efficiency; as brown strain has lower values than the black strain. The results show the inverse relationship between feed efficiency and feed conversion ratio, and that good and profitable egg production is achieved when feed efficiency is higher coupled with lower feed conversion ratio.

Feed restriction has significant $(\mathrm{P}<0.01)$ effect on feed intake, feed efficiency and feed conversion ratio as shown in Table 1 . The birds fed ad libitum consumed more feeds than those fed $90 \%$ and $80 \%$ ad libitum. It was also shown that those fed $90 \%$ ad libitum has higher feed intake than $80 \%$ ad libitum. The reduced feed intake by birds in $90 \%$ and $80 \%$ ad libitum was due to the imposition of feed restriction on them. The birds in the two groups had limited and restricted access to daily ration when compared to ad libitum birds. Similar results have also been reported by other workers in the literature [16]. The authors indicated that feed restriction decreased average daily feed consumption in broiler female breeder hens. With regard to feed efficiency, restricted birds in $90 \%$ ad libitum has higher and superior $(\mathrm{P}<0.01)$ mean values to ad libitum and $80 \%$ ad libitum. In feed conversion ratio, $90 \%$ ad libitum recorded lower and better mean values than the other two treatments. The results indicate that quantitative feed restriction improves feed utilization during late production period, and that birds fed $90 \%$ ad libitum utilized their feeds efficiently than ad libitum and $80 \%$ ad libitum. The former therefore, could be recommended to farmers judging from higher mean values obtained on hen-day production and feed efficiency. Adoption of milder feed restriction seems to hold good prospect for increased production, profit and sustainability of egg producing industry. In partial agreement with these results, previous researcher found significant improvement in feed conversion ratio in birds fed $80 \%$ ad libitum [17]. On the contrary, some authors have reported that at late laying period, feed restriction has no significant effect on birds' production [8]. 


\subsection{Egg Quality Traits}

\subsubsection{Effect of Strain}

There was no significant $(\mathrm{P}>0.01)$ effect of strain on all the egg quality traits measured at 55 weeks of age with the exception of albumen height and Haugh unit (Table 2). Also, at 57 weeks (Table 3 ), no significant $(\mathrm{P}>0.05)$ effect of strain was observed in all the egg quality traits measured with the exception of shell thickness. The two strains subjected to feed restriction recorded similar mean values and performed equally well in egg weight, egg length and other external and internal egg qualities. But in albumen height and Haugh unit, brown birds had higher $(\mathrm{P}<0.01)$ mean values than black hens. Haugh unit is a determinant of internal egg quality, the higher the value, the higher the nutritive value of an egg. In this study, Isa Brown eggs with higher HU were adjudged superior in egg quality and could be recommended for human consumption and egg processing industry. In partial agreement with these results, reference [8] reported that Brown strain had higher HU values than white strain only at early and mid-age production periods. It is interesting to note that there was progressive increase in egg weight and other egg quality traits including Haugh unit as the birds advanced in age across strains.

The results of the present study also reveal that brown hens produced eggs with stronger shell than black hens. This is an important and another distinguishing genetic difference between the two layer strains. It is desirable that eggs meant for home use and hatchery have stronger shell in order to prevent breakages and microbial spoilage. Therefore, in places where storage facility is non-existent, it is expected that brown strain eggs will remain healthy and good after some length of time due to its stronger shell if not exposed to extremely hot temperature.

Table 1. Least squares mean showing the effect of strain and feed restriction of production traits of commercial layers.

\begin{tabular}{cccccc}
\hline Factors & Egg number & Egg percentage & $\begin{array}{c}\text { Traits } \\
\text { Feed intake }\end{array}$ & Feed efficiency & Feed conversion ratio \\
\hline Strains & & & & & \\
IB & $11.54 \pm 0.18$ & $77.35 \pm 1.19^{\mathrm{a}}$ & $1433.33 \pm 13.69$ & $0.0081 \pm 0.0001^{\mathrm{a}}$ & $0.126 \pm 0.0029^{\mathrm{b}}$ \\
BN & $11.05 \pm 0.23$ & $73.57 \pm 1.53^{\mathrm{b}}$ & $1433.33 \pm 13.69$ & $0.0076 \pm 0.0001^{\mathrm{b}}$ & $0.134 \pm 0.0021^{\mathrm{a}}$ \\
Feed restriction & & & & & \\
$100 \%$ & $11.98 \pm 0.21^{\mathrm{a}}$ & $79.76 \pm 1.42^{\mathrm{a}}$ & $1600 \pm 0.00^{\mathrm{a}}$ & $0.0075 \pm 0.0001^{\mathrm{b}}$ & $0.137 \pm 0.0028^{\mathrm{a}}$ \\
$90 \%$ & $11.68 \pm 0.23^{\mathrm{a}}$ & $77.86 \pm 1.50^{\mathrm{a}}$ & $1400 \pm 0.00^{\mathrm{b}}$ & $0.0084 \pm 0.0001^{\mathrm{a}}$ & $0.122 \pm 0.0025^{\mathrm{b}}$ \\
$80 \%$ & $10.21 \pm 0.26^{\mathrm{b}}$ & $68.77 \pm 1.78^{\mathrm{b}}$ & $1300 \pm 0.00^{\mathrm{c}}$ & $0.0077 \pm 0.0002^{\mathrm{b}}$ & $0.132 \pm 0.0036^{\mathrm{a}}$ \\
\hline
\end{tabular}

abc: means along columns with different superscripts are significantly different $(\mathrm{P}<0.01)$

IB- Isa Brown

BN- Bovan Nera

Table 2. Effect of feed restriction on egg quality traits of layer strains at 55 weeks of age.

\begin{tabular}{|c|c|c|c|c|c|c|c|c|c|c|}
\hline \multirow{2}{*}{ Factors } & \multicolumn{10}{|c|}{ Traits (55 weeks) } \\
\hline & EWT & $\mathrm{EL}$ & EW & YWT & $\mathrm{YH}$ & AWT & $\mathrm{AH}$ & $\mathrm{HU}$ & SWT & $\mathrm{ST}$ \\
\hline \multicolumn{11}{|l|}{ Strains } \\
\hline IB & $62.97 \pm 1.19$ & $6.07 \pm 0.09$ & $4.87 \pm 0.11$ & $15.97 \pm 0.27$ & 2.330 .08 & 38.540 .57 & $1.32 \pm 0.06^{\mathrm{a}}$ & $110.90 \pm 1.89^{\mathrm{a}}$ & $8.26 \pm 0.11$ & $0.56 \pm 0.02$ \\
\hline $\mathrm{BN}$ & $61.10 \pm 1.59$ & $6.19 \pm 0.08$ & $4.69 \pm 0.04$ & $15.93 \pm 0.30$ & $2.22 \pm 0.07$ & $37.66 \pm 1.25$ & $1.14 \pm 0.06^{\mathrm{b}}$ & $104.77 \pm 2.11^{\mathrm{b}}$ & $7.78 \pm 0.24$ & $0.57 \pm 0.02$ \\
\hline \multicolumn{11}{|l|}{$\begin{array}{l}\text { Feed } \\
\text { restriction }\end{array}$} \\
\hline $100 \%$ & $61.48 \pm 1.20$ & $5.98 \pm 0.08$ & $4.82 \pm 0.11$ & $15.68 \pm 0.26$ & $2.23 \pm 0.08$ & $37.85 \pm 0.78$ & $1.17 \pm 0.11$ & $105.11 \pm 3.75$ & $7.85 \pm 0.31$ & $0.58 \pm 0.02^{\mathrm{a}}$ \\
\hline $90 \%$ & $63.37 \pm 2.09$ & $6.17 \pm 0.14$ & $4.88 \pm 0.13$ & $16.15+0.31$ & $2.28 \pm 0.11$ & $39.18+1.66$ & $1.23 \pm 0.04$ & $107.96 \pm 1.46$ & $8.18 \pm 0.23$ & $0.53+0.02^{\mathrm{b}}$ \\
\hline $80 \%$ & $61.25 \pm 1.92$ & $6.23+0.08$ & $4.63+0.06$ & $16.02 \pm 0.45$ & $2.31+0.10$ & $37.27 \pm 0.96$ & $1.30 \pm 0.08$ & $110.43 \pm 2.43$ & $8.01 \pm 0.20$ & $0.57 \pm 0.02^{\mathrm{ab}}$ \\
\hline
\end{tabular}

EWT-egg weight EL-egg length EW-egg width YWT-yolk weight YH-yolk height AWT-albumen weight AH-albumen height HU-haugh unit SWT-shell weight ST-shell thickness

ab means along the columns with different superscripts are significantly different (no superscripts implies the means are similar) IB: Isa Brown BN: Bovan Nera

Table 3. Effect of feed restriction on egg quality traits of layer strains at 57 weeks of age.

\begin{tabular}{|c|c|c|c|c|c|c|c|c|c|c|}
\hline \multirow{2}{*}{ actors } & \multicolumn{10}{|c|}{ Traits (57 weeks) } \\
\hline & EWT & EL & EW & YWT & $\mathrm{YH}$ & AWT & $\mathrm{AH}$ & $\mathrm{HU}$ & SWT & ST \\
\hline \multicolumn{11}{|l|}{ Strains } \\
\hline IB & $63.14 \pm 0.80$ & 6.030 .08 & $4.83 \pm 0.08$ & $14.89 \pm 0.28$ & 2.260 .06 & 40.180 .72 & $1.33 \pm 0.056$ & $111.34 \pm 1.59$ & $8.38 \pm 0.20$ & $0.43 \pm 0.02^{\mathrm{a}}$ \\
\hline $\mathrm{BN}$ & $63.26 \pm 4.47$ & $6.24 \pm 0.07$ & $4.86 \pm 0.08$ & $14.93 \pm 0.31$ & $2.31 \pm 0.05$ & $40.31 \pm 1.32$ & $1.28 \pm 0.04$ & $109.45 \pm 1.57$ & $8.32 \pm 0.28$ & $0.38 \pm 0.02^{\mathrm{b}}$ \\
\hline \multicolumn{11}{|c|}{ Feed restriction } \\
\hline $100 \%$ & $64.67 \pm 0.99$ & $6.08 \pm 0.10$ & $4.92 \pm 0.11$ & $15.12+0.27$ & $2.33 \pm 0.03$ & $41.47 \pm 1.23$ & $1.18 \pm 0.30^{\mathrm{b}}$ & $105.92 \pm 1.23^{\mathrm{b}}$ & $8.52 \pm 0.29$ & $0.40 \pm 0.03$ \\
\hline $90 \%$ & $63.30 \pm 1.46$ & $6.17 \pm 0.11$ & $4.85 \pm 0.08$ & $14.48+0.45$ & $2.27 \pm 0.09$ & $40.68+1.12$ & $1.38+0.06^{\mathrm{a}}$ & $112.98+1.88^{\mathrm{a}}$ & $8.08+0.28$ & $0.40 \pm 0.03$ \\
\hline
\end{tabular}

ab means along the columns with different superscripts are significantly different (no superscripts implies the means are similar).

EWT-egg weight EL-egg length EW-egg width YWT-yolk weight YH-yolk height AWT-albumen weight

AH_albumen height HU-haugh unit SWT-shell weight ST-shell thickness

IB: Isa Brown BN: Bovan Nera 


\subsection{Economic Efficiency and Mortality Rate}

Feed restriction has highly significant $(\mathrm{P}<0.01)$ effect on total feed intake, total feed cost, net revenue and economic efficiency (Table 4). Total feed cost $(\$ /$ hen) was highest $(\mathrm{P}<0.01)$ for control birds but decreased by feed restriction during the experimental period. The reduction in feed cost represented about $3.7 \%$ and $7.41 \%$ for $90 \%$ ad libitum and $80 \%$ ad libitum, respectively compared to those feed ad libitum. The reduction in total feed cost as a result of feed restriction could be attributed to the negative effect of quantitative feed restriction on total feed consumption. The highest net revenue and economic efficiency was recorded in $90 \%$ ad libitum, intermediate and lowest in ad libitum and $80 \%$ ad libitum, respectively. The superiority of $90 \%$ ad libitum in net revenue and economic efficiency over other two groups could be attributed to the better feed conversion and higher feed efficiency (Table 1), total egg number per hen and to the total egg price recorded by the former. The result agrees with the previous study [18]. The researchers opined that net egg income over feed cost increased significantly by quantitative feed restriction. On the contrary, reference [8] reported no significant differences in net revenue between the different feeding regimens imposed on the birds.

Mortality rate in this study was none for control and feed restricted birds. This might be due to the short duration of the experiment. In partial agreement with this study, [16] stated that conventional feed restriction decreased mortality rate in broiler breeder females compared to ad libitum feeding after peak of lay. Similarly, [17] reported that mortality rate was insignificant between layers fed $a d$ libitum and $80 \%$ ad libitum restricted feeding regimen.

In this study strain has significant $(\mathrm{P}>0.5)$ effect on egg production per hen, net revenue and economic efficiency, but the reverse was the case for feed consumption and feed cost per hen (Table 4). Isa Brown strain achieved higher $(\mathrm{P}<0.01)$ net revenue per hen than Bovan Nera at the end of the experimental period. This superiority $(6.08 \%)$ could be attributed to the better feed conversion and higher feed efficiency (Table 1), total eggs number per hen and to the total egg price produced by Isa Brown strain compared to Bovan Nera (Table 4). Total feed cost on strain basis in the present study did not influence net returns, but total eggs per hen and market price of eggs did. The obtained result was similar to the findings of [8] who reported significant differences between strains in feed conversion, total egg number per hen and total egg price per hen. The researchers also found significant strain differences in net return per hen; which is also corroborated this study .. Isa Brown appeared good, feed and economic efficient and suitable for profitable rearing under feed restriction regimen.

Table 4. Cost implication and economic efficiency of feed restricted laying hens during 4 weeks.

\begin{tabular}{|c|c|c|c|c|c|c|c|c|c|}
\hline \multirow{2}{*}{ Classification } & \multicolumn{2}{|c|}{$\begin{array}{l}\text { FeedIntake } \\
\text { (kg) }\end{array}$} & \multicolumn{2}{|c|}{$\begin{array}{c}\text { Feed Cost @ } \\
\$ 0.625 / \mathrm{kg}\end{array}$} & \multirow{2}{*}{$\begin{array}{c}\text { Total } \\
\text { Eggs/Hen }\end{array}$} & \multirow{2}{*}{$\begin{array}{c}\text { Total Egg } \\
\text { Price/Hen } \\
\text { @ } \$ 0.125 / \text { egg }\end{array}$} & \multirow{2}{*}{$\begin{array}{c}\text { Net } \\
\text { RevenuePer } \\
\text { Hen(\$) }\end{array}$} & \multirow{2}{*}{$\begin{array}{c}\text { Relative } \\
\text { EconomicEfficiency }(\%)\end{array}$} & \multirow{2}{*}{$\begin{array}{c}\text { Mortality } \\
\text { (\%) }\end{array}$} \\
\hline & Total & $\begin{array}{l}\text { Per } \\
\text { Hen }\end{array}$ & Total & $\begin{array}{l}\text { Per } \\
\text { Hen }\end{array}$ & & & & & \\
\hline \multicolumn{10}{|l|}{ A. Treatments } \\
\hline ad libitum & 92.40 & 3.08 & 57.75 & 1.93 & 23.93 & 2.99 & 1.06 & 100 & - \\
\hline $90 \%$ & 83.16 & 2.77 & 51.98 & 1.73 & 23.36 & 2.92 & 1.19 & 112.26 & - \\
\hline $80 \%$ & 73.92 & 2.46 & 46.20 & 1.54 & 20.43 & 2.55 & 1.01 & 95.28 & - \\
\hline \multicolumn{10}{|l|}{ B. Strains } \\
\hline IB & 124.74 & 2.77 & 77.96 & 1.73 & 21.53 & 2.69 & 0.96 & 100 & - \\
\hline $\mathrm{BN}$ & 124.74 & 2.77 & 77.96 & 1.73 & 20.60 & 2.58 & 0.85 & 88.54 & - \\
\hline
\end{tabular}

IB: Isa Brown $\quad$ BN: Bovan Nera

$\$=\$ 160$ (Nigerian currency)

\section{Conclusion}

From these results, it can be concluded that strain differ in their response to feed restriction. Brown strain appeared tolerant to short-term feed restriction than black strain. The former recorded higher and significant values in percent egg production, feed efficiency, net revenue and economic efficiency than the latter. In addition, brown strain obtained better and higher Haugh unit than black strain. With regard to feed restriction levels, $90 \%$ ad libitum was better and feed efficient than ad libitum and $80 \%$ ad libitum. The former also recorded higher net returns and economic efficiency. Brown birds and $90 \%$ ad libitum show promise and could be recommended for improved productivity and profit maximization

\section{Acknowledgments}

The author is indebted to the Staff of Teaching and Research Farm, Ekiti State University, Ado-Ekiti for their support and assistance during the period of data collection.

\section{References}

[1] D.D. Bell and W.D. Weaver. "Commercial chicken meat and egg production". $5^{\text {th }}$ edition, Cambridge, Massachussets. Kluwer Academic Publisher, 2002. 
[2] L. Kostal, C. J. Savory and B. O. Hughes. "Diurnal and individual variation in behaviour of restricted-fed broiler breeders". Applied Animal Behaviour, 32, pp. 361-374, 1992.

[3] C. J. Savory, E. Seawright and A. Watson. "Stereotyped behaviour in broiler breeders in relation to husbandry and opioid receptor blockade". Applied Animal Behaviour, 32, pp. 349-360, 1992.

[4] P. J. W. Lee, A. L. Gulliver and T. R. Morris. "A quantitative analysis of the literature concerning the restricted feeding of growing pullets". Br. Poultry Sci., 12, pp. 413-437, 1971.

[5] S. N. Ukachukwu and U. O. Akpan. "Effect of quantitative feed restriction on the performance and laying characteristics of pullets". Tropical and Subtropical Agroecosystems, 7, pp. 15-20, 2007.

[6] S. Leeson and J. D. Summers. "Feeding programmes for broilers: Commercial Poultry Nutrition. University Books, Guelph, pp. 207-254, 1997.

[7] A. O. Fasuyi and O. G. Ojo. "Quantitative feed restriction threshold in Bovan Nera laying pullets in the warm wet tropics”. J. Animal Sci. Advances, 2(1), pp. 158-165, 2012.

[8] A. M. A. Osman, M. A. Toson, S. A. Abdel-Latif, H. H. M. Hassanien and T. M. A. Marwan. "Effect of fasting on reproductive performance of laying hens". Egypt Poultry Sci., 30(4), pp. 1031-1057, 2010

[9] R. S. Gowe, A. S. Johnson, F. D. Crawford, J. H. Downs, A. T. Hill, M. F. Mountain, J. R. Pelletier and J. H. Strain. "Restricted versus full feeding during the growing period for egg production stock". Br Poultry Sci., 1, pp. 37-56, 1960.

[10] R. Blair, M. M. McCowan and W. Bolton. "Effect of food regulation during the growing and laying stages on the productivity of broiler breeders". Br. Poultry Sci., 39, pp. 205-212, 1976.

[11] D. Balnave. " The effect of feeding low protein diets on pullets from hatch to point of lay, the quantitative restriction of food during the subsequent laying period". Br. Poultry Sci., 15 , pp. 395-403, 1974.

[12] S. O. Olawumi and I. Dudusola. "Assessment of long-term production traits of three breeds of exotic commercial layers in the Derived savannah zone of Nigeria”. J. Applied and Natural Sci., 3(1), pp. 20-24, 2011.

[13] Statistical Analysis System, SAS Users Guide. Statistics, $8^{\text {th }}$ edition, SAS Institute Cary, NC, USA, 2001.

[14] F. G. Silversides, D. R. Korver and K. L. Budgell. "Effect of strain of layer and age at photo-stimulation on egg production, egg quality and bone strength". Poultry Sci., 85, pp. 1136-1144, 2006.

[15] J. V. Felts. "Dietary self-selection and feed restriction studies with growing and breeding turkeys". Ph.D Dissertation. Virginia Polytechnic Institute and State University, Blacksburg, Virginia, USA, 1993.

[16] A.Al-Nasser, A. Al-Saffar, M. Mashaly, H. Al-Khalaifa, F. Khalil, M. Albaho, and A. Al-Haddad. "A comparative study on production efficiency of white and brown pullets". World's Poultry Sci., 62, pp. 296-307, 2006.

[17] P. M. Hocking, R. Bernard and G. W. Robertson. "Effects of low dietary protein and different allocations of food during rearing and restricted feeding after peak rate of lay on egg production, fertility and hatchability in female broiler breeders". Br. Poultry Sci., 43, pp. 94-103, 2002.

[18] R. Hasnath. "Effect of feeding systems on the egg production of Fayoumi hens of model breeding units under PLDP programme in Bangladesh". M.Sc. Thesis, department of Animal Science and Animal Health and Network for Smallholder Poultry Development, Bangladesh, 2002.

[19] P. N. Mbugua and D. L. Cunningham. "Effects of feed restriction on production performance of replacement pullets”. Poultry Sci., 62, pp. 1169-1176, 1983. 